\title{
Usefulness of the Ultrasound in Hand Surgery: Part I
}

\section{Utilidad de la ecografía en la cirugía de la mano: parte I}

\author{
Homid Fahandezh-Saddi Díaz ${ }^{1,4}$ \\ Manuel Villanueva Martínez ${ }^{4}$ \\ ${ }^{1}$ Hand Surgery Unit, Hospital Universitario Fundación Alcorcón, \\ Alcorcón, Madrid, Spain \\ 2 Orthopedic Surgery and Traumatology Unit, Clínica Pakea de \\ Mutualia, Donostia/San Sebastián, Guipúzcoa, País Vasco, Spain \\ ${ }^{3}$ Musculoskeletal Radiology Service, Hospital Universitario Fundación \\ Alcorcón, Alcorcón, Madrid, Spain \\ ${ }^{4}$ Orthopedic Surgery and Traumatology Unit, clínica AVANFI, Madrid, \\ Madrid, Spain \\ ${ }^{5}$ SERMAS institution, Madrid, Spain
}

Ángel Bueno Horcajadas 3 (0)

Rev Iberam Cir Mano 2021;49(2):e128-e139.

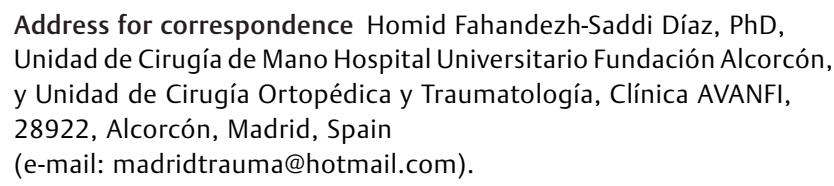
Unidad de Cirugía de Mano Hospital Universitario Fundación Alcorcón, y Unidad de Cirugía Ortopédica y Traumatología, Clínica AVANFI, 28922, Alcorcón, Madrid, Spain

(e-mail: madridtrauma@hotmail.com).

\begin{abstract}
Keywords

- hand

- ultrasound-guided procedures

In the last years, ultrasonography (US) of the wrist and hand have increased in popularity. Technical advances led us to improve image quality and have the ability to see superficial soft-tissue structures with high resolution with the patient in our office.

The advantages of US are the fact that it is noninvasive, its lack of ionising radiation, low cost, and portability. The dynamic real-time assessment in the office is an additional benefit.

Ultrasound can be used in hand surgery for both diagnostic and therapeutic purposes. We can use US for injections with needle guidance, for the evaluation of soft-tissue masses, foreign bodies, tendon injuries, compressive neuropathies, and rheumatologic joint disease. It also helps us perform ultrasound-guided procedures: carpal tunnel syndrome, trigger finger, and intersection syndrome or compartimental syndrome. The aim of the present review is to describe different uses of US in hand surgery to show its important role of providing to the surgeon more information on the diseases of their patients.
\end{abstract}

received

September 13, 2021 accepted after revision October 1, 2021
DOI https://doi.org/ $10.1055 / \mathrm{s}-0041-1739295$. ISSN 1698-8396.

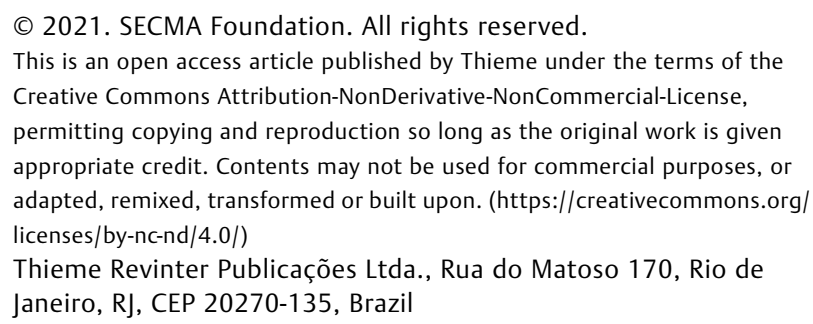
Creative Commons Attribution-NonDerivative-NonCommercial-License, permitting copying and reproduction so long as the original work is given appropriate credit. Contents may not be used for commercial purposes, or adapted, remixed, transformed or built upon. (https://creativecommons.org/ licenses/by-nc-nd/4.0/) Thieme Revinter Publicações Ltda., Rua do Matoso 170, Rio de Janeiro, RJ, CEP 20270-135, Brazil 


\section{Resumen \\ Palabras clave \\ - mano \\ - procedimientos guiados por ecografía \\ En los últimos años, la ecografía de muñeca y mano ha aumentado en popularidad. Los avances técnicos nos llevaron a mejorar la calidad de la imagen y a tener la capacidad de ver estructuras superficiales de tejidos blandos con alta resolución con el paciente en nuestro consultorio. \\ Las ventajas de la ecografía son el hecho de que es no invasiva, su falta de radiación ionizante, el bajo costo y la portabilidad. La evaluación dinámica y en tiempo real en el consultorio es un beneficio adicional. \\ El ultrasonido puede ser utilizado en la cirugía de la mano con fines diagnósticos y terapéuticos. Podemos utilizar la ecografía para inyecciones con guía de aguja, para la evaluación de masas de tejidos blandos, cuerpos extraños, lesiones de tendones, neuropatías compresivas, y enfermedad articular reumatológica. También nos ayuda a realizar procedimientos guiados por ecografía: síndrome del túnel carpiano, dedo en gatillo, síndrome de intersección, o síndrome compartimental. \\ El objetivo de la presente revisión es describir diferentes utilidades de la ecografía en cirugía de mano que muestran el importante papel de la ecografía en ayudar al cirujano a tener más información de la enfermedad del paciente.}

\section{Introduction}

The popularity of ultrasonography (US) of the wrist and hand, has increased in the last years. Technical advances, such smaller probe sizes and new ultrahigh frequency probes, led to an improvement in image quality and gave us the ability to see superficial soft-tissue structures in high resolution, with the patient in our office. ${ }^{1}$

Normally, when we use conventional ultrasound, the transducers work with frequencies that range from $5 \mathrm{MHz}$ to $12 \mathrm{MHz}$. These relative low frequencies enable the US to penetrate deeply into the body to visualize target internal structures. Ultrahigh frequency ultrasound (UHFUS) is capable of producing frequencies of up to $70 \mathrm{MHz}$, which enables us to see superficial anatomical structures. With this technology, we can achieve tissue resolution of up to $30 \mu \mathrm{m}$ ( 3 to 4 times smaller than the average diameter of a volar digital nerve in the hand). ${ }^{1}$

The advantages of US are the fact that it is noninvasive, its lack of ionising radiation, low cost, and portability. The dynamic real-time assessment in the office is an additional benefit. ${ }^{2}$

Moreover, Doppler imaging helps the hand surgeon find neurovascular structures that are really important when performing an ultrasound-guided surgery.

Ultrasound can be used in hand surgery for both diagnostic and therapeutic purposes. We can use US for injections with needle guidance, and for the evaluation of soft-tissue masses, foreign bodies, tendon injuries, compressive neuropathies, and rheumatologic joint disease. It also helps us perform ultrasound-guided procedures: carpal tunnel syndrome, trigger finger, tntersection syndrome, or compartimental syndrome. ${ }^{1}$

The aim of the present review is to describe different uses of ultrasound in Hand Surgery that show its important role in helping the surgeon obtain more information on the patient's disease, know more about the patient's anatomy for the surgical procedure, and describe different ultrasound-guided surgical techniques.

\section{Masses and Foreign Bodies}

Previous studies ${ }^{3-5}$ have demonstrated the use of conventional ultrasound to obtain images of common soft-tissue masses in the hand.

Ganglions cysts are the most common lesions of the hand and wrist. Most ganglion cysts arise from the dorsum of the wrist. On US, they are classically well-defined, lobulated hypoechoic cystic masses with posterior acoustic enhancement. A tail may be observed extending to the adjacent joint or tendon. Ultrasound helps define the diagnosis, and it also enables the surgeon to identify the site and to ensure the surgical treatment and the evacuation of the wrist ganglion. The injection of methylene blue prior to arthroscopic resection helps to find the capsular stalk. 6,7

\section{-Figure 1}

\section{-Figure 2A,B}

Giant-cell tumours of the tendon sheath are the second most common lesions of the hand and wrist. They arise from the tendon sheath and can progressively enlarge, causing erosions to the adjacent bone. These lesions most commonly, involve the volar surface of the fingers. On US, they are welldefined solid hypoechoic masses with vascularity

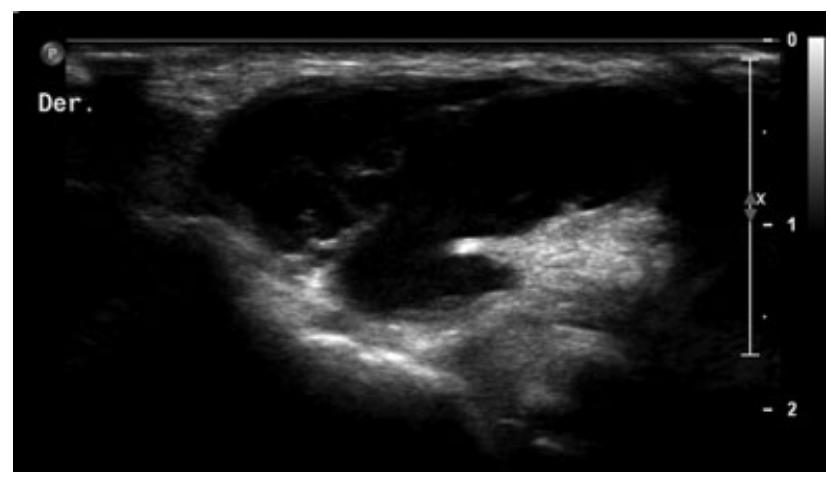

Fig. 1 Radiocarpal ganglion cyst 

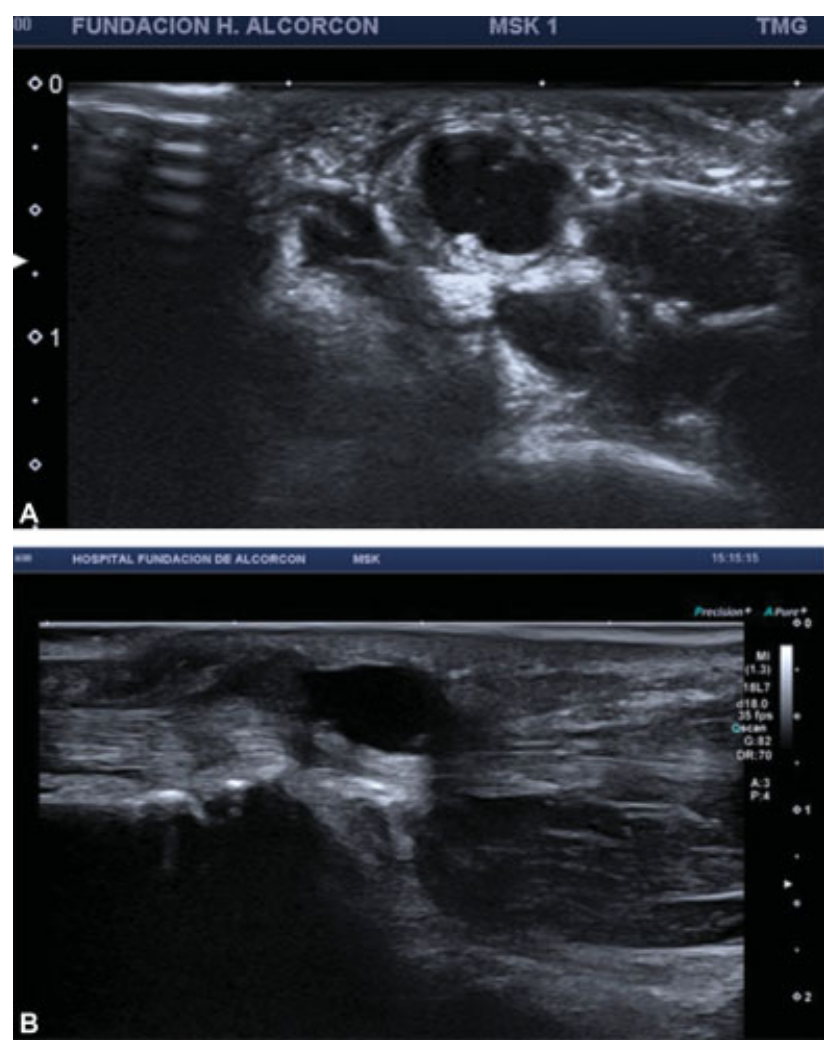

Fig. 2 (A,B) Transverse and longitudinal axes of an intratendinous ganglion cyst

demonstrated on color Doppler US. On the dynamic assessment, these lesions do not move with the tendons. ${ }^{8}$

-Figure 3A-C

Vascular malformations (VMs) are common soft-tissue lesions of the hands and wrist. These lesions are especially

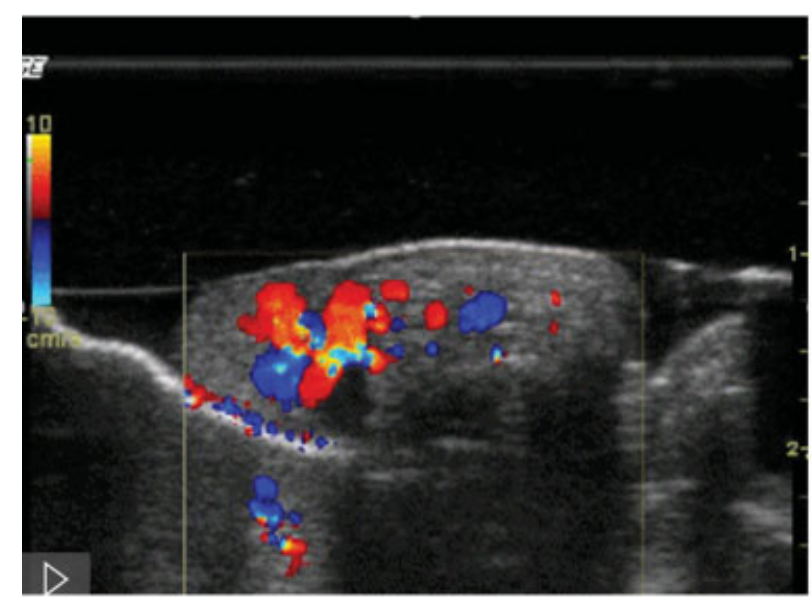

A
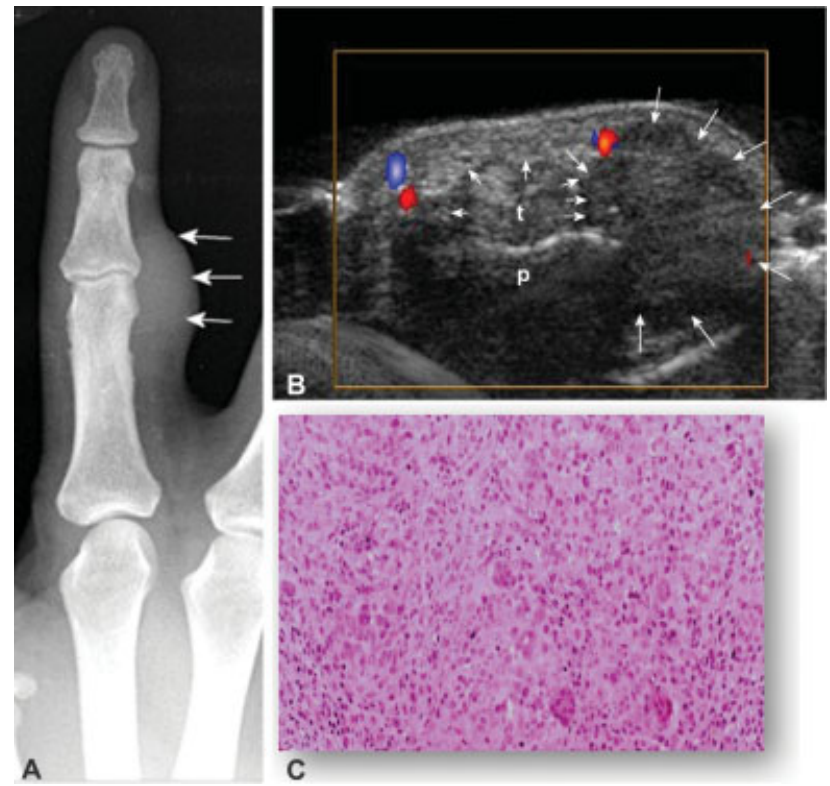

Fig. 3 (A-C) Giant-cell tumor

observed in young adults, and they represent $10 \%$ of benign tumours. On US, they have a variable appearance, of compressible solid echoic or hypoechoic masses with cystic serpiginous areas representing dilated vessels and fat tissue. They are classified as high- or low-flow based on the vascularity on Doppler US. Venous low-flow VM may show small calcifications in relation to phleboliths. A typical true hemangioma at the top of the finger is the lobular capillary hemangioma (or pyogenic granuloma) with high arterial flow. ${ }^{8,9}$

-Figure 4A,B

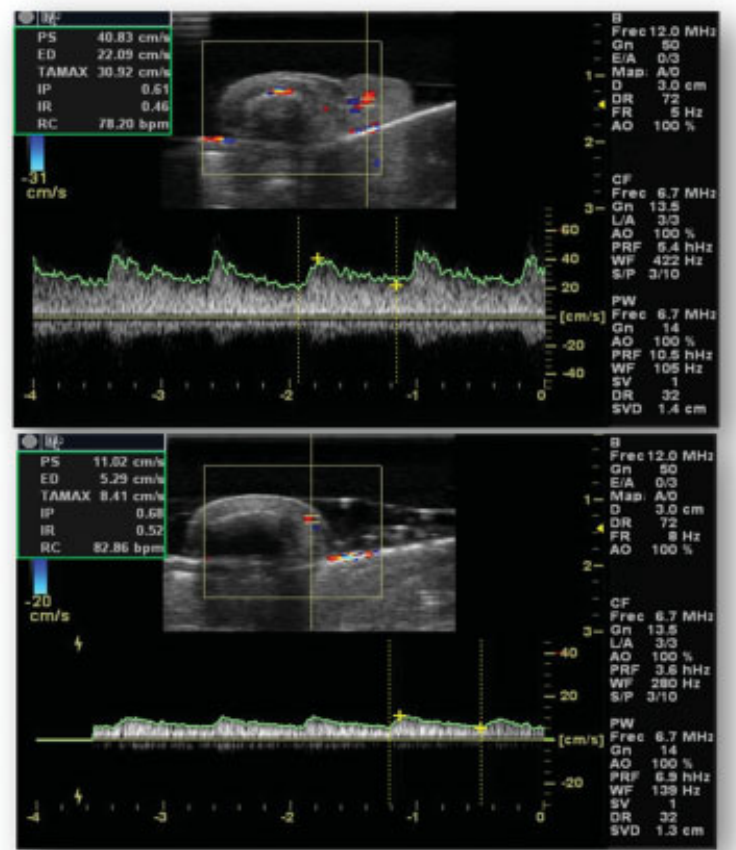

B

Fig. 4 (A,B) Lobular capillary hemangioma 

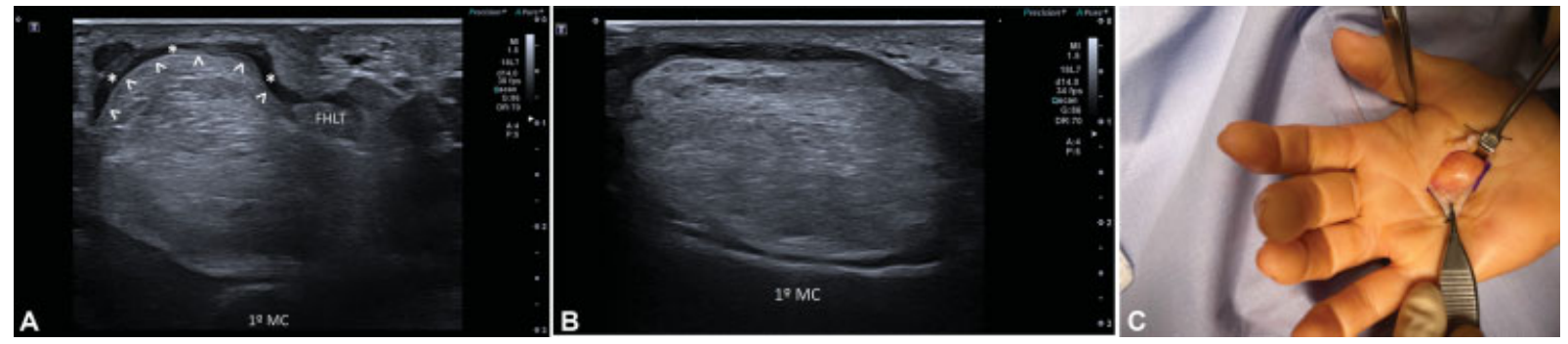

Fig. 5 (A-C) Axial and longitudinal US lipoma and intraoperative correlation

Fibrolipomatous hamartomas are rare lesions that most commonly affect the median nerve and its branches. The symptoms include pain and paraesthesia along the distribution of the involved nerve, due to the proliferation of fibroadipose tissue from the nerve sheath. On US, there is enlargement of the involved nerve with splaying of the nerve fascicles by a proliferation of slightly echoic fatty tissue. ${ }^{8,9}$

\section{Lipomas}

Simple benign lipomas are the most common kind of softtissue tumor, but they are infrequent in the hand.

On ultrasound, lipomas are well-demarcated lesions that are classically described as hyperechoic and homogeneous. However, they may be hypoechoic or isoechoic. Superficial lipomas may be difficult to visualize, as they may blend in with the adjacent fat. On magnetic resonance imaging (MRI), they show a fat signal with homogeneous high signal on T1weighted and low signal on short-tau inversion recovery (STIR) or T2 fat-saturated images. Septations may be observed in cases of benign lipomas, but nodules or solid components indicate an atypical lipoma or liposarcoma. In intramuscular lipomas, fatty tissue infiltrates between the muscle fibers. ${ }^{8-10}$

-Figure 5A-C

\section{Foreign Bodies}

Ultrasound is especially useful in assessing radiolucent foreign bodies, such as wood or glass. Additionally, it is possible to stablish their chronicity related to the surrounding granulation tissue or scar and accurately localize them in order to plan their removal. In the field of surgical treatment, ultrasound assistance enables the direct control of the procedure with minimal skin wound; however, an old or organic foreing body could be difficult to remove; therefore, open resection should be favored. ${ }^{10,11}$

\section{Malignant Tumours}

Malignant lesions of the hand and wrist are uncommon, and those that are seen on US are mostly soft-tissue sarcomas. Metastases are less common.

The different types of soft-tissue sarcomas have similar non-specific US appearances. They are usually bigger and irregular heterogeneous masses with necrosis, and with vascularity shown on color Doppler US. Upon suspicion of malignancy, MRI is mandatory before biopsy, for a proper preoperative evaluation.
The biopsy can be performed percutaneously guided by ultrasound, with a correct technique. ${ }^{11}$

\section{Tendon Injuries}

Tendons can be visualized as a hyperechoic fibrilar structure on a longitudinal plane. Atention to the characteristic anisotropy artifact of the tendons when the ultrasound beam is not perpendicular to the long axis of the tendon. It is very important to check the insonation angle and to demonstrate the alteration on the two perpendicular US images.

The pulley system of the flexor tendon sheath keeps the tendon close to the underlying phalanges, which causes it to course in a curvilinear fashion along the skeletal structures of the finger. As a result, the tendon will exhibit differential areas of hyperechogenicity and hypoechogenicity. The tendons can be easily identified and tracked from the wrist to their insertions. ${ }^{12,13}$

\section{-Figure 6A,B}

\section{Flexor Tendons and Pulley System}

a) Flexor tendons: in the fingers, the flexor digitorum superficialis (FDS) and flexor digitorum profundus (FDP) can be clearly visualized from the level of the metacarpophalangeal (MCP) joint, through the Camper chiasm, and to their individual insertions. At the level of the proximal interphalangeal (PIP) joint, the FDP tendon is observed superficial to the FDS tendon.

With UHFUS, the volar plate is clearly visualized as a hyperechoic structure spanning between the flexor tendon and the hyperechoic cortical area of the metacarpal or phalanx head.

Ultrasound is the best technique to display dynamic realtime visualization. When a patient extends the finger, the tendons are observed gliding within the tendon sheath and exerting traction on the phalanges to extend the joints. We can follow the tendon from proximal to distal, and verify the normal gliding, the presence of adhesions, and also identify tendon injuries. ${ }^{12-16}$

Tears of the flexor tendons are usually associated with penetrating injury rather than contusions. In cases such as those of Jersey finger injuries, the FDP injury, is secondary to traction in sports. In flexor tendons tears, US is useful in determining if the tear is partial or complete. It can also locate the exact site of rupture and the degree of retraction of the torn ends, which is essential to plan 

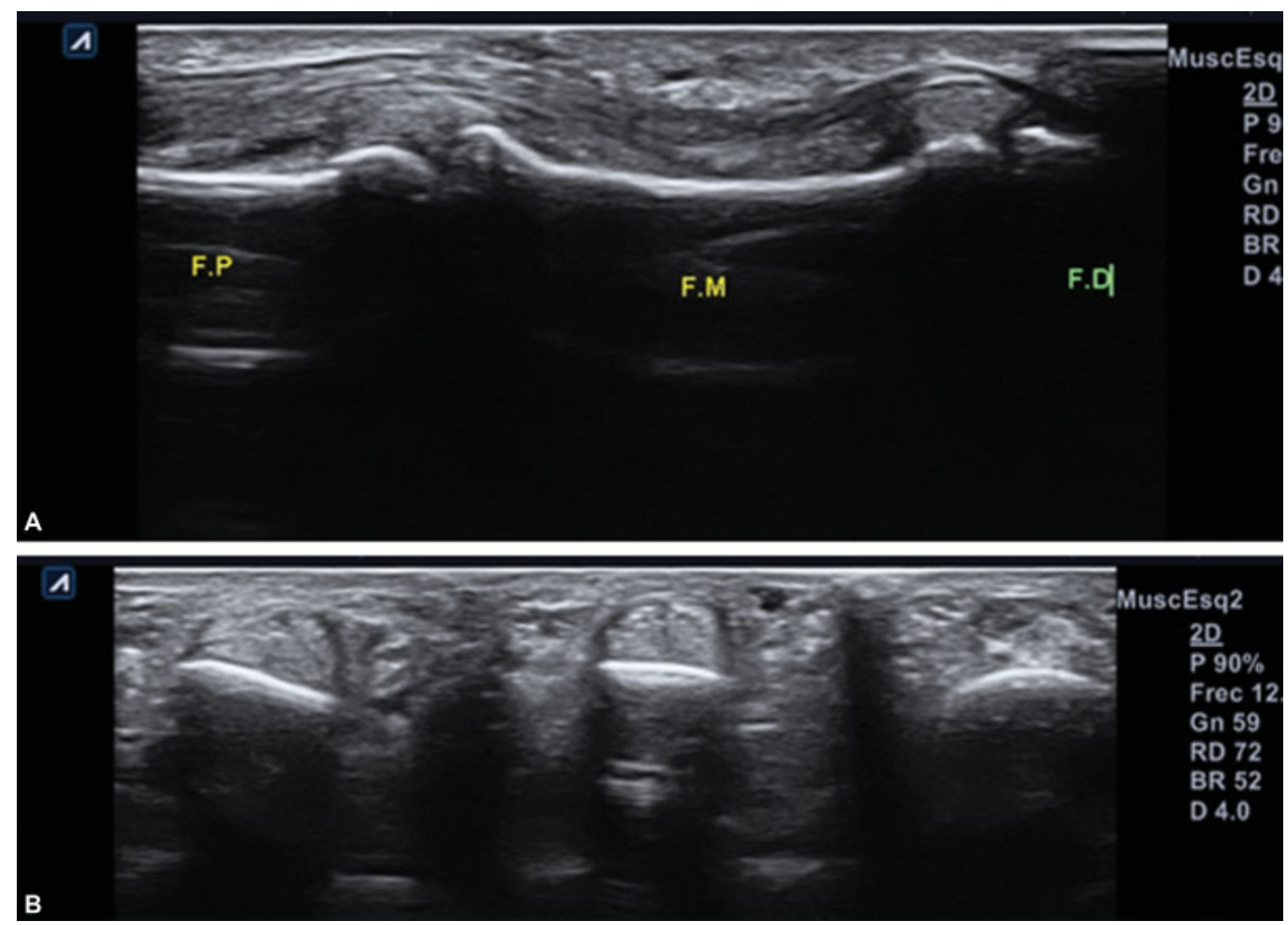

Fig. 6 (A,B) Flexor tendon anatomy

reconstructive surgery and to minimize the morbidity of the approach.

Postoperatively, US is useful in the follow-up to identify suture dehiscence or entrapment due to fibrosis, and in the dynamic assessment during active and passive movements. Complete tears are easy to identify as a complete rupture of the normal fibrillar tendon fibers and lack of tendon movement on dynamic assessment. It is important to check the tear in both planes (axial and transverse). Partial tendon tears are difficult to evaluate on US and appear as focal hypoechoic areas within the tendon. Tendon tears may often be longitudinal, along the length of the tendon.

With UHFUS, additional information is obtained on the mechanics of the flexor mechanism with this type of dynamic imaging. For example, when the finger is actively flexed and the probe is placed within zone II of the flexor tendons, the two FDS excursions are seen moving from volar to dorsal to the FDP.

b) The pulley system in the hands is composed of focal thickenings in the flexor tendon sheaths on the volar aspect, which prevents tendon excursion during flexion. Loss of this pulley system results in impaired digital function. Two types of pulleys are identified, the annular pulleys (A1-A5) and the cruciform pulleys (C1-C3). The A2 pulley, which lies in the proximal third of the proximal phalanx, and the A4 pulley, which lies across the middle phalanx, appear to be the two most important pulleys for precise flexor tendon function.

On UHFUS, we can identify the pulley system. They are seen as thin hyperechoic bands found anterior to the flexor tendons. Tears result in the disruption of these bands with bowing of the flexor tendon on flexion against resistance. $^{17}$

The diagnosis of pulley tear is stablish by assesing the tendon-to-bone distance: $>3 \mathrm{~mm}$ for A2 tears, and $2.5 \mathrm{~mm}$ for A4 tears. ${ }^{16-19}$

\section{-Figure 7}

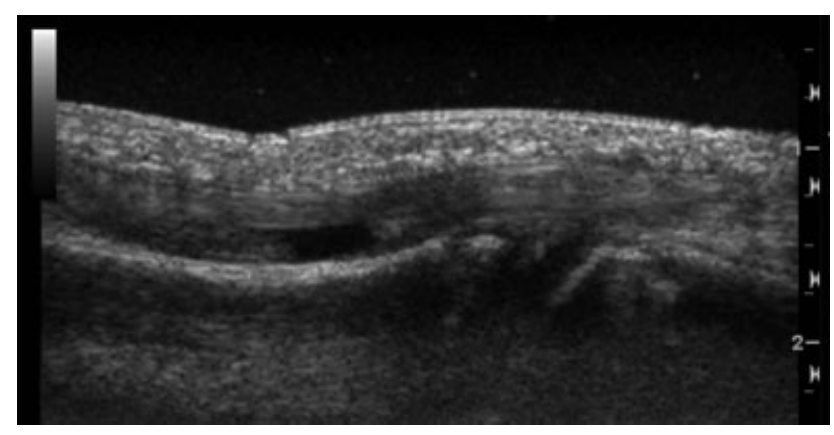

Fig. 7 FDS tear 
-Figure 8A-C

-Figure 9A-C

-Figure 10A-D

-Figure 11

\section{Extensor Tendons}

In the dorsum of the hand, the extensors are easily found beneath the dermis overlying the bright hyperechoic rim of the metacarpals and the dorsal interosseous muscles.
Tears of the extensor tendons are commonly a sequela of rheumatoid tenosynovitis. Other cases may be due to direct injury or contusions.

As with flexor tendon tears, US is useful in determining if the tear is partial or complete, and in locating the exact site of the rupture and the degree of retraction for surgery planning. ${ }^{5}$

-Figure 12

-Figure 13

-Figure 14A, B
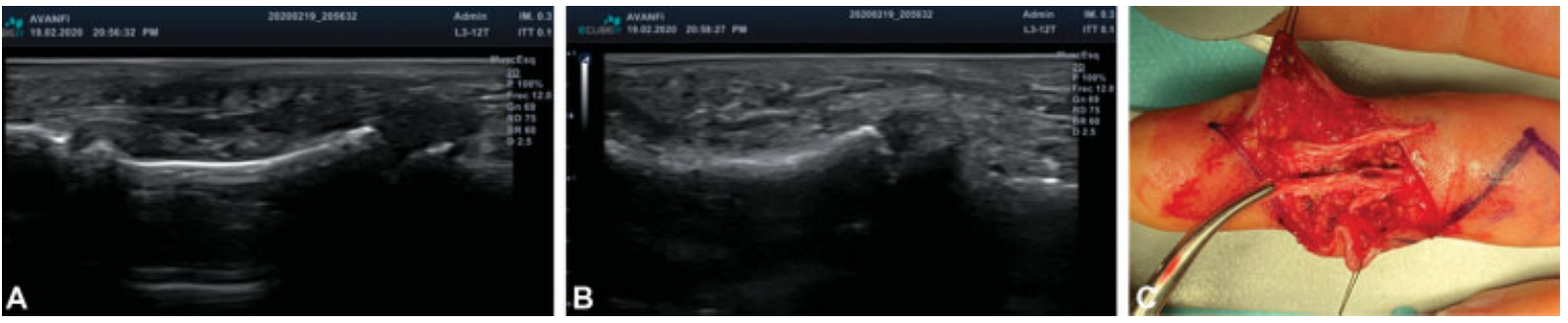

Fig. 8 (A-C) FDS tear in rock climber
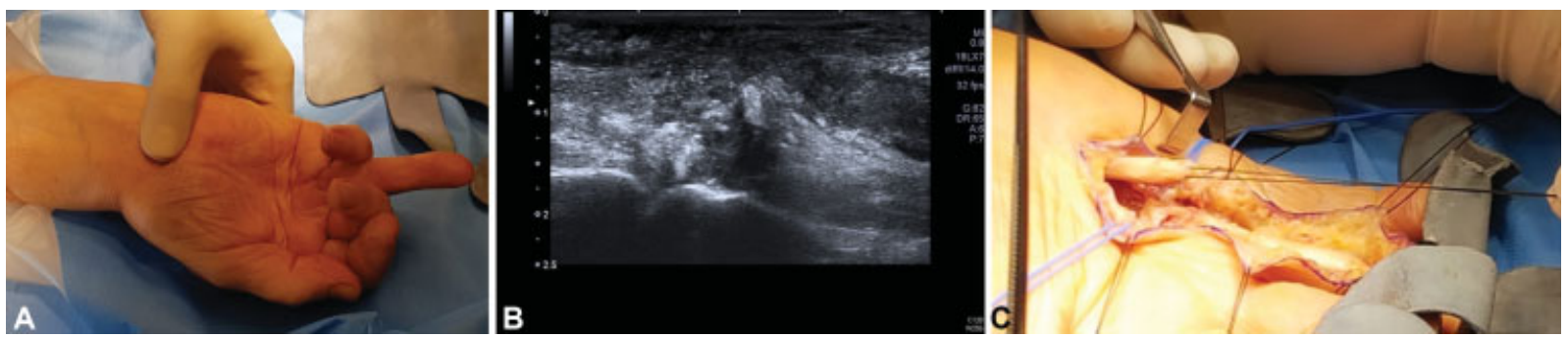

Fig. 9 (A-C) Flexor tendon tear
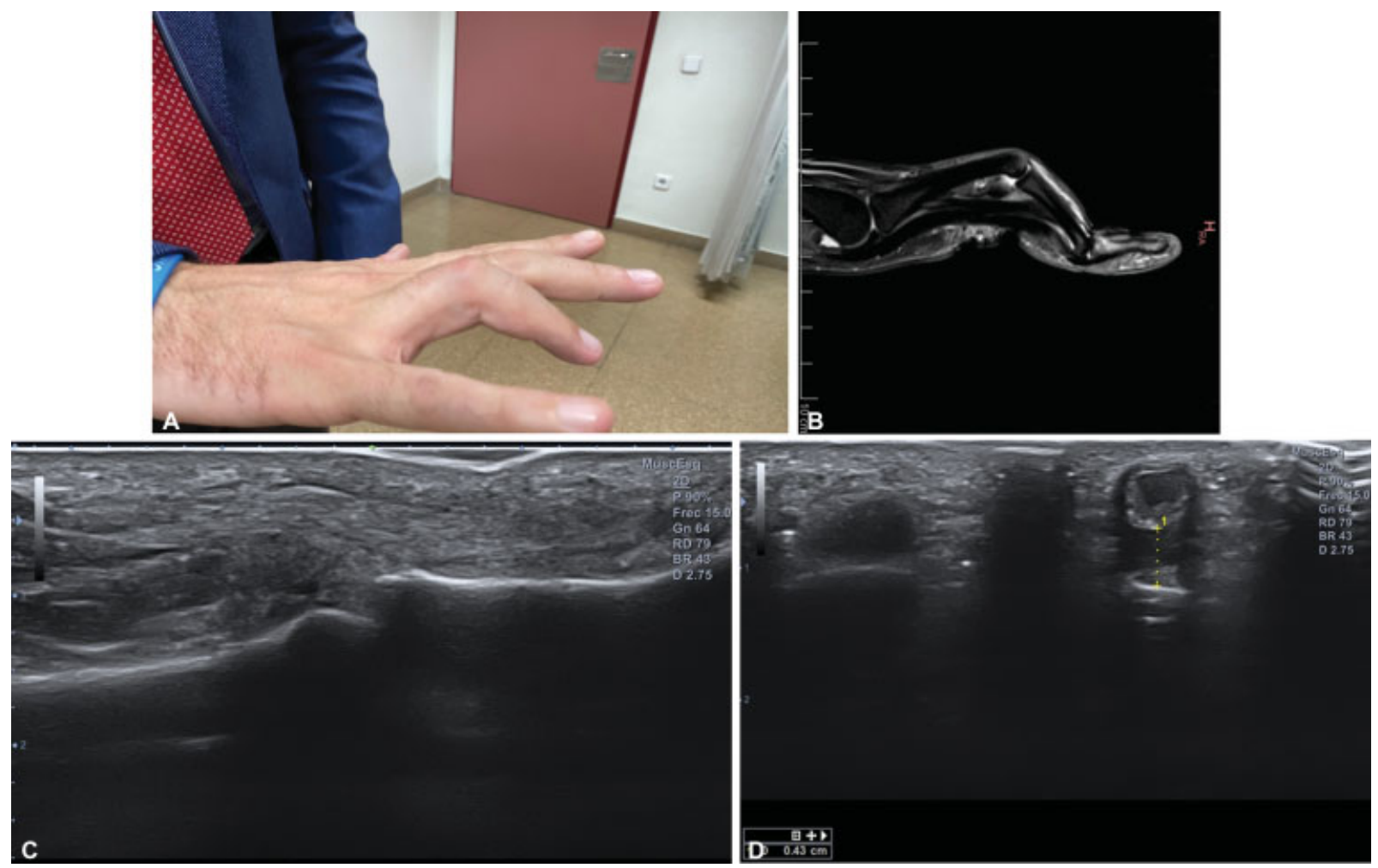

Fig. 10 (A-D) Pulley rupture 


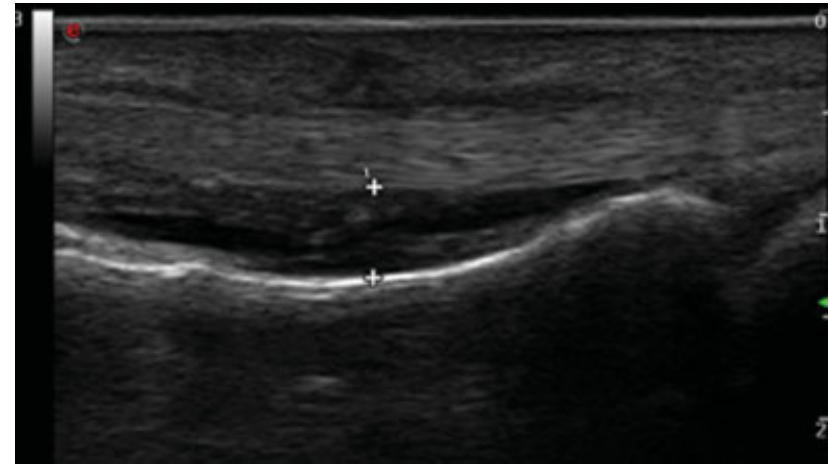

Fig. 11 A2 pulley rupture

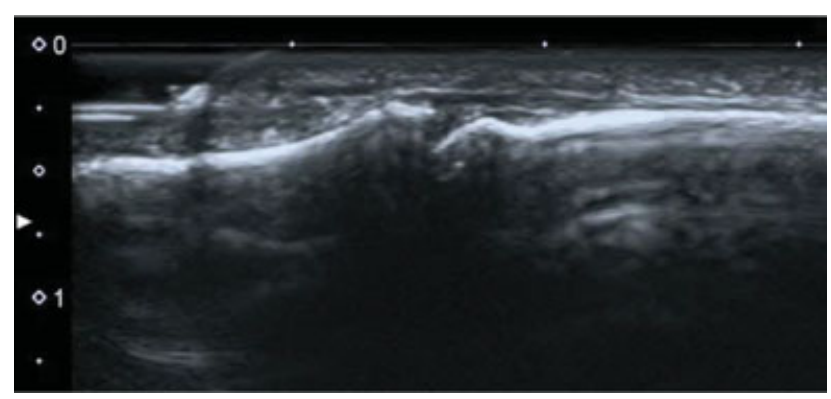

Fig. 12 Normal anatomy of the distal extensor tendon

\section{Nerve Injuries}

These injuries are commonly observed following traumatic penetrating injuries or surgical amputation. Often as a sequela, the formation of traumatic neuroma is observed at the end of the severed nerve or at the repair site. These represent disorganised neural tissue that grows at the ends of the severed nerve and can cause continued symptoms of pain and paraesthesia. On US, a traumatic neuroma is observed as a well-defined hypoechoic bulbous mass arising from the nerve sheath at the severed end.

Ultrasound help us to observe the continuity of the nerve and also perform a nerve block in the case of a painful neuroma to ensure that, with surgery, the patient is going to feel better and the pain will disappear. ${ }^{20-22}$

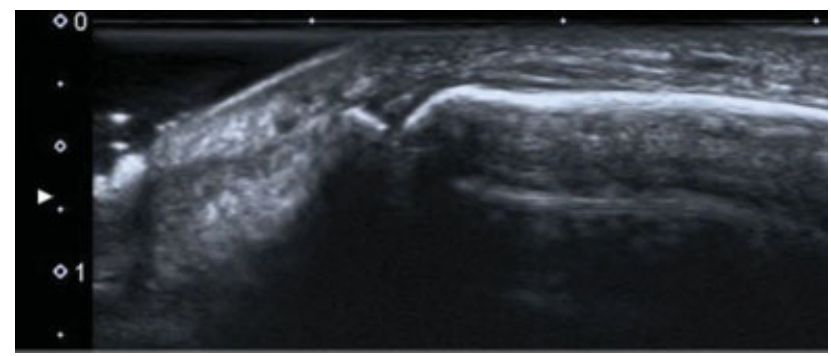

Fig. 13 Distal disruption of the distal extensor tendon

\section{-Figure 15A,B}

\section{Peripheral Nerve Tumors}

The hand and wrist are common locations of some peripheral nerve tumors, which are defined by an enlarged image in the continuity of the nerve.

a) Schwannomas: US diagnosis is established through well-defined hypoechoic ovoid images with eccectric location, sparing the nerve fascicle located around de tumor. In big tumors, internal degeneration with hypoechoic images and Doppler signal are common. ${ }^{8}$

b) Neurofibromas which arises from a group of fascicles, are visualized by a central lesion without fascicle sparring and an onion-shaped structure with variable echogenicity. The target sign (hypoechoic periphery and central hyperechogenicity) is common in neurofibromas. They may show predominant peripheral Doppler vascularization. $^{8}$

In the presence of a nerve tumor, US enables the scanning of the whole nerve path and of other peripheral nerves in order to discard type-1 neurofibromatosis. ${ }^{1}$

\section{-Figure 16A-D}

\section{Bone Fractures}

In patients treated for hand injuries, fractures are the most frequent lesions (42\%), followed by lesions to the tendons (29\%) and skin, as showed in the study by Schöffl et al. ${ }^{12}$
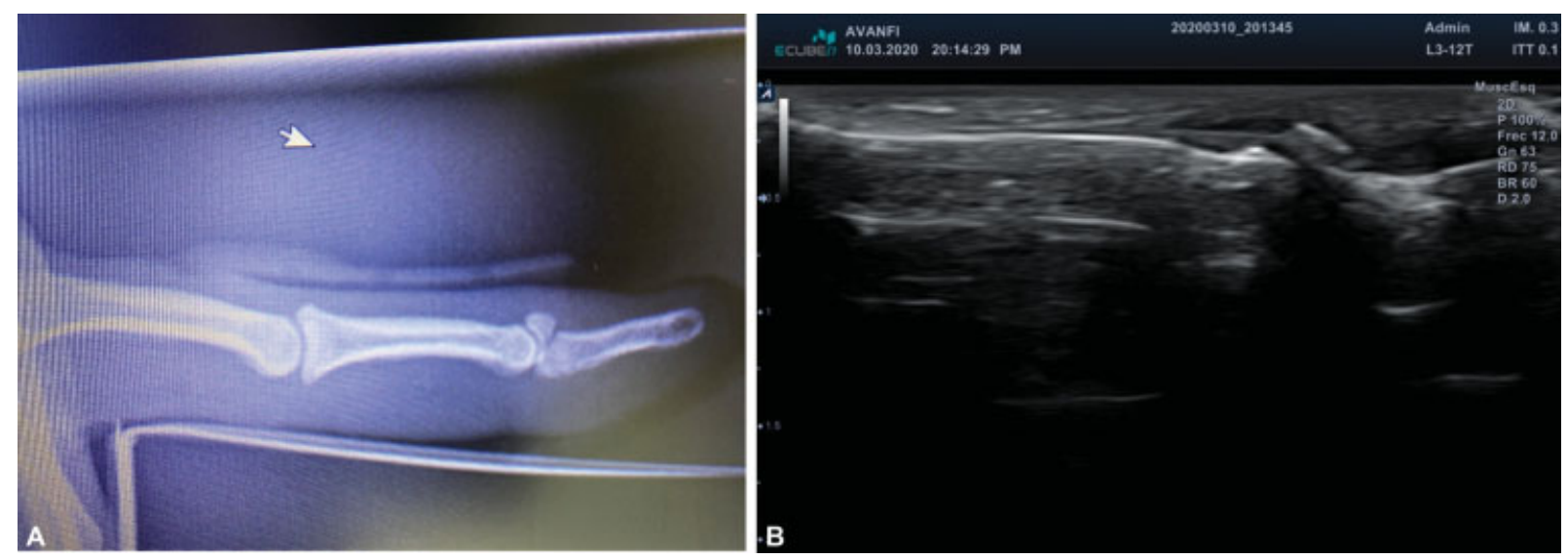

Fig. $14(A, B)$ Mallet finger fracture 

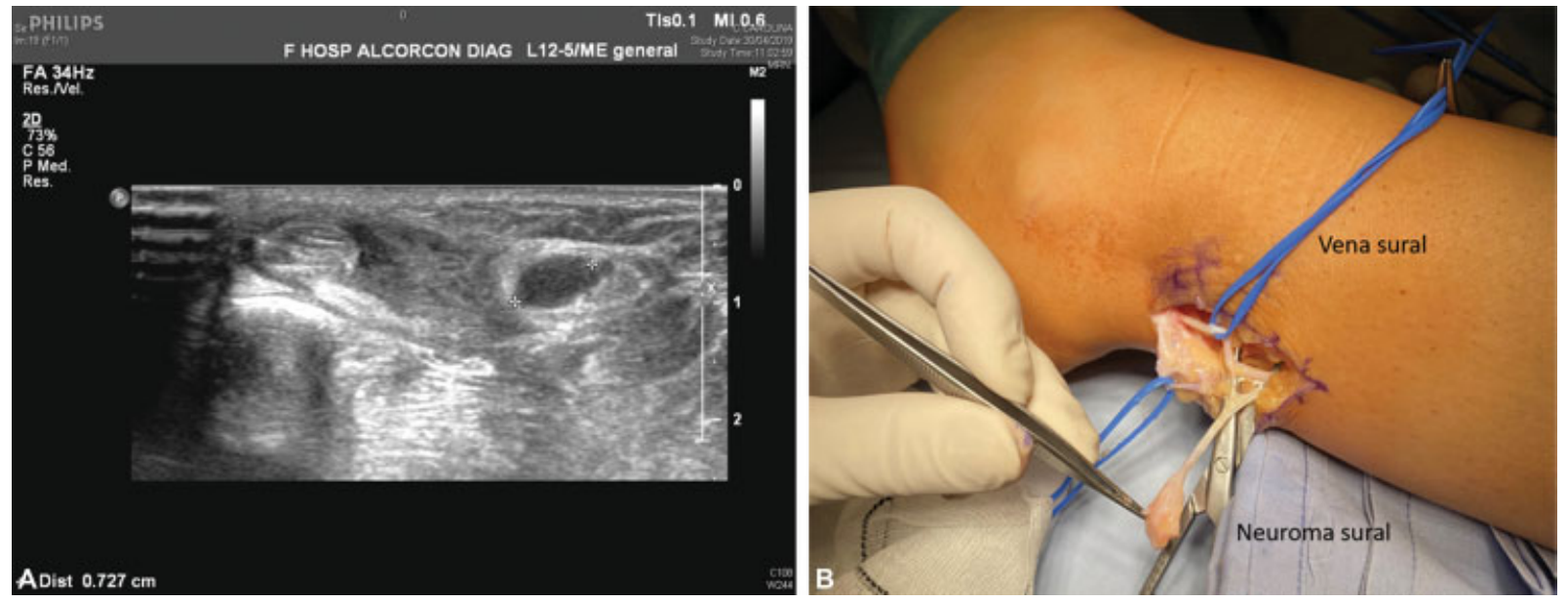

Fig. 15 (A,B) Sural neuroma after peroneal surgery. Ultrasound and correlation with intraoperative findings
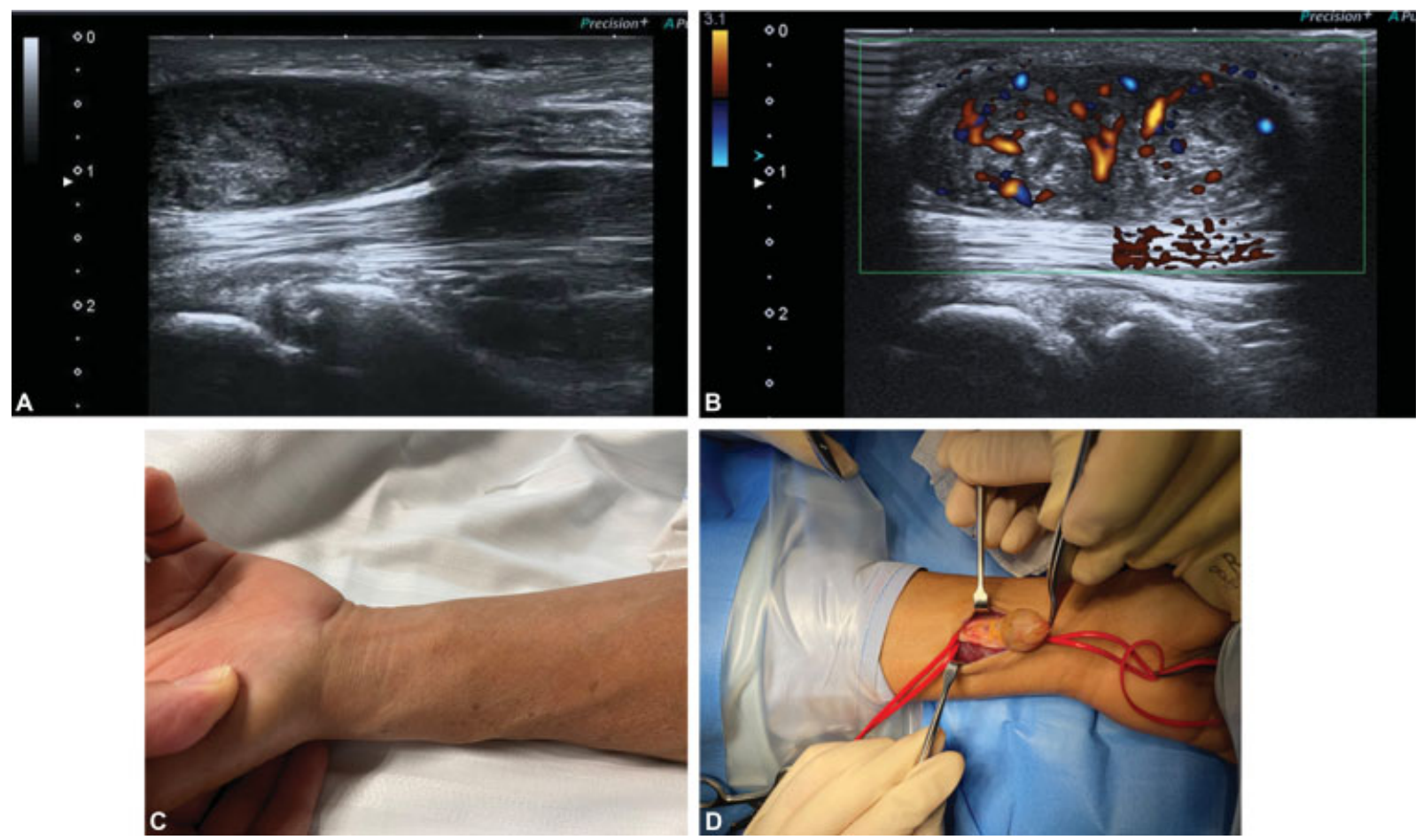

Fig. 16 (A-D) Median schwannoma

Even if the diagnosis of fractures is still mainly based on conventional radiography (CR), or computed tomography (CT) or MRI scans, US is a highly-accurate method for the evaluation of the bone surface, and is able to detect even small, occult irregularities of the bone cortex. ${ }^{22-25}$

Fractures appear as the interruption of the hyperechoic line of the cortical area of the bone, with hypoechoic periosteal thickening and surrounding soft-tissue edema. Increased hyperemia at the fracture site is possible. If cortical irregularity can be easily observed in the dyaphysis of long bones, in epiphyseal bone or irregular ones the US beam needs to be oblique, which may result in the loss of details. its significance in the diagnosis of irregular bone fractures, especially those to the scaphoid, shows that US might be valuable even in patients without changes in CR. At the same time, studies ${ }^{12}$ have shown that US can depict more fractures than $\mathrm{CR}$, and should be considered an alternative for the more expensive and less available MRI and CT. In a recently-published case report ${ }^{14}$, fractures secondary to hyperextension of the thumb, of both the ulnar and radial sesamoids of the MCP joint of the thumb were diagnosed by US and confirmed by CT. When an irregular bone fracture is suspected and the CR is negative, MRI or CT scans can be used to confirm the US results. Furthermore, US can be used to 


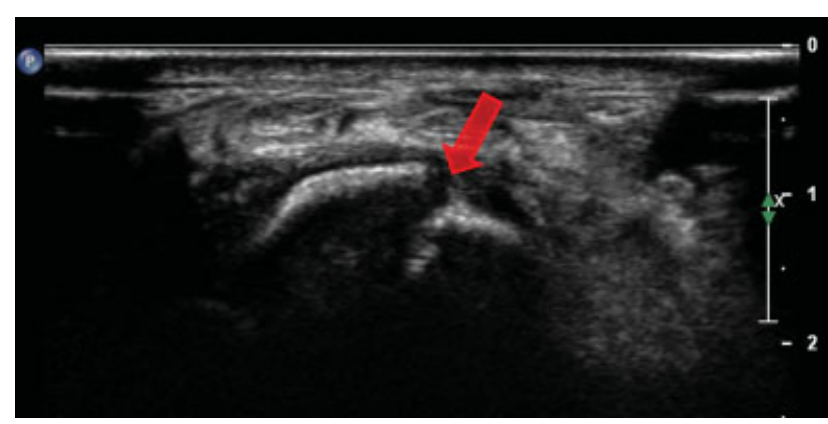

Fig. 17 Scaphoid fracture

identify the formation of new bone, before it is visible on $C R$, as echoic foci at the fracture site, which become aligned in the long axis, while fluid in the distraction gap might suggest a low rate of formation of new bone. The dynamic evaluation is another advantage of US, besides its availability and multiplanar capability, which can show fracture non-union during active or passive movements. ${ }^{22-25}$

-Figure 17

\section{Ligament Injuries}

Wrist ligament injuries, including those in the scapholunate or lunotriquetral ligaments, might be visible through an US examination. We can perform dynamic studies and compare the normal hand with the injured one, to observe well the ligament and evaluate its competence with dynamic studies.

The intrinsic and extrinsic ligaments of the wrist consist of bundles of parallel-oriented type-I collagen fibers, and they show a fibrillar pattern on US examination. The US beam must be directed as perpendicular as possible to the evaluated structure in order to avoid anisotropy. The assessment of carpal ligaments is achieved with commercially-available high-frequency linear-array transducers, typically of $12 \mathrm{MHz}$ or higher. ${ }^{26,27}$

A large amount of US gel is recommended for the optimal visualization. ${ }^{28,29}$ The patient sits opposite to the operator, with the hand and forearm lying on a flat surface.

Wrist ligaments are primarily visualized along their longitudinal axis, and they appear as fibrillar structures deeper than wrist tendons; an examination of the short axis may be helpful to confirm the imaging findings. A tear is suspected if the ligament fibers are discontinuous, or if the ligament is not observed in the expected anatomic location. ${ }^{28,29}$

Dynamic manoeuvres can be performed to stress the wrist joint and produce tension in the carpal ligaments.

\section{Palmar Extrinsic and Intrinsic Midcarpal Ligaments}

The palmar extrinsic and intrinsic midcarpal ligaments are examined with the wrist in supination; the dynamic manoeuvre of wrist extension is valuable to best detect the ligaments along their entire length.
On the radial side of the volar wrist, the transducer is placed in the longitudinal plane using the radial styloid process as the starting anatomic landmark. It is then translated distally and medially and slightly rotated in order to assess, from lateral to medial, the radioscaphocapitate, long radiolunate and short radiolunate ligaments. ${ }^{28,29}$

On the ulnar side of the volar wrist, the probe is placed in the longitudinal plane using the ulnar styloid process as the starting anatomic landmark. Thereafter, we can visualize, from medial to lateral, the palmar ulnotriquetral, palmar ulnocapitate, and palmar ulnolunate ligaments. The volar midcarpal ligaments include the palmar scaphotriquetral, scaphotrapeziotrapezoid, scaphocapitate, triquetrohamate, and triquetrocapitate ligaments. Among them, only the palmar scaphotriquetral ligament has been described in US studies. ${ }^{28,29}$ It is examined by positioning the transducer in the transverse plane on the radial side of the volar wrist, over the distal radius as the starting anatomic landmark. The transducer is shifted distally and translated medially along the first carpal row to visualize the palmar scaphotriquetral ligament along its entire length.

\section{Dorsal Extrinsic and Intrinsic Midcarpal Ligaments}

The dorsal extrinsic and intrinsic midcarpal ligaments include the dorsal radiocarpal and the dorsal intercarpal ligaments respectively.

They are examined with the wrist in pronation; the dynamic manoeuvre of wrist flexion may help in strengthening the ligaments and appreciating their full length.

On the dorsal wrist, the transducer is positioned in the transverse plane using the Lister tubercle as the starting anatomic landmark. The transducer is then shifted distally and slightly rotated toward the lunate and triquetrum to identify the dorsal radiocarpal ligament.

The dorsal radiocarpal ligament arises from the radius, distally to the Lister tubercle, and inserts into the lunate and triquetrum; it is deeper than the fourth extensor compartment of the wrist.

The dorsal intercarpal ligament, also known as the dorsal scaphotriquetral ligament, arises from the triquetrum and emits a proximal band inserting into the scaphoid and a distal band terminating on the trapezoid, thus having a Vshaped configuration; it may also have additional attachments to the lunate or trapezium.

In order to evaluate the proximal band of the dorsal intercarpal ligament, from the position previously described, the probe is rotated with its radial edge toward the scaphoid and then aligned along the first carpal row. Thereafter, the probe is pointed at the triquetrum and further rotated with its radial edge toward the trapezoid to identify the distal band of the ligament.

High rates of visibility on US have been previously reported for both dorsal and volar palmar extrinsic and intrinsic midcarpal ligaments. 


\section{Intrinsic Interosseus Ligaments}

The proximal interosseus ligaments consist of both a volar and a dorsal band connected at their proximal pole, thus dividing the radiocarpal and midcarpal joint spaces.

The volar bands of the proximal interosseus ligaments are evaluated with the wrist in supination; slight wrist extension creates tension in the ligaments and then optimizes their visualization.

On the volar aspect of the wrist, the transducer is placed in the transverse plane using the distal radius as the starting anatomic landmark. It is shifted distally and then medially along the first row of carpal bones in order to identify, from radial to ulnar, the volar band of the scapholunate and lunotriquetral ligaments.

The dorsal bands of the proximal interosseous ligaments are examined with the wrist in pronation; the dynamic manoeuvre of wrist flexion may help in strengthening the ligaments. On the dorsal side of the wrist, the transducer is positioned in the transverse plane over the Lister tubercle as the starting anatomic landmark. It is then translated distally and moved in the ulnar direction along the first carpal row to identify, from radial to ulnar, the dorsal bands of the scapholunate and lunotriquetral ligaments. ${ }^{30-33}$

Both the volar and dorsal bands of the scapholunate and lunotriquetral ligaments are visualized as triangular structures that connect the scaphoid and lunate and the lunate and triquetrum. ${ }^{34,35}$ On the volar aspect of the wrist, the scapholunate and lunotriquetral ligaments intertwine with the extrinsic long radiolunate and ulnocapitate ligaments respectively.

The distal interosseus ligaments separate the midcarpal and carpometacarpal joint spaces and include, from radial to ulnar, the trapeziotrapezoid, trapezocapitate, and capitohamate ligaments. Although accessible for the US assessment, the distal interosseus ligaments do not usually need to be examined in the routine clinical practice, as they are extremely powerful and seldom undergo tears.

\section{Extrinsic Collateral Ligaments}

The extrinsic collateral ligaments described in the radiology literature represent capsular thickenings more than proper ligaments. ${ }^{33,34}$

The ability of the US to assess the extrinsic collateral ligaments is controversial, as some authors have reported poor detection rates. ${ }^{34}$

In the hand, US is also able to identify, in the fifth finger, the ulnar collateral ligament; in the index finger, the radial collateral ligament; and, in the thumb, both collateral ligaments of the MCP and interphalangeal (IP) joints. ${ }^{36,37}$

a) Injuries to the ulnar collateral ligaments (UCLs) of the thumb

These are common in the practice of sports. Most frequently, lesions to the UCL occur especially while skiing ("skier's thumb"). The normal UCL is hyperechoic and can be identified on the ulnar side of the MCP joint, deep in a thin hyperechoic band which corresponds to adductor pollicis aponeurosis.

The spectrum of UCL injuries of the thumb include: strain, partial thickness tear, full thickness tear, and associated findings (bone avulsion, volar plate injury, or Stener lesion).

For the US diagnosis of Stener lesion, dynamic exploration flexing the IP joint of the thumb is mandatory: the excursion of the adductor pollicis aponeurosis is interrupted by the retracted ulnar ligament.

Ultrasound may help differentiate six types of skier's thumb and indicate surgical or conservatory treatment, with splints or casts.

b) Lesion of the radial collateral ligament (LCR)

This injury is less common. Due to the intrinsic anatomy of the radial side of the first MCP joint, combined with the dynamic force of the adductor pollicis tendon, those lesions usually lead to a rapid pathologic process, with joint instability and progressive volar subluxation.

The appearance on US is similar to that of UCL lesions, apart from the changes related to Stener lesions. ${ }^{36,37}$

c) Volar plate injuries

Considered a ligament, the volar plate is another structure frequently involved in sport injuries.

On US, it appears as a triangular echoic structure deep in the flexor tendons, which gets displaced from the bony surface.

Volar plate injuries are the result of forced hyperextension in the MCP joint, and might be oberved on US as a mixed hypo-hyperechoic irregular area involving the echogenic structure of the volar plate. If the injury is associated with a characteristic phalangeal avulsion fracture, the fragment can be identified through US as a hyperechoic image, with an acoustic shadow. ${ }^{29}$

In the next chapter (part II), we will describe ultrasoundguided procedures and other minimally-invasive techniques in hand surgery.
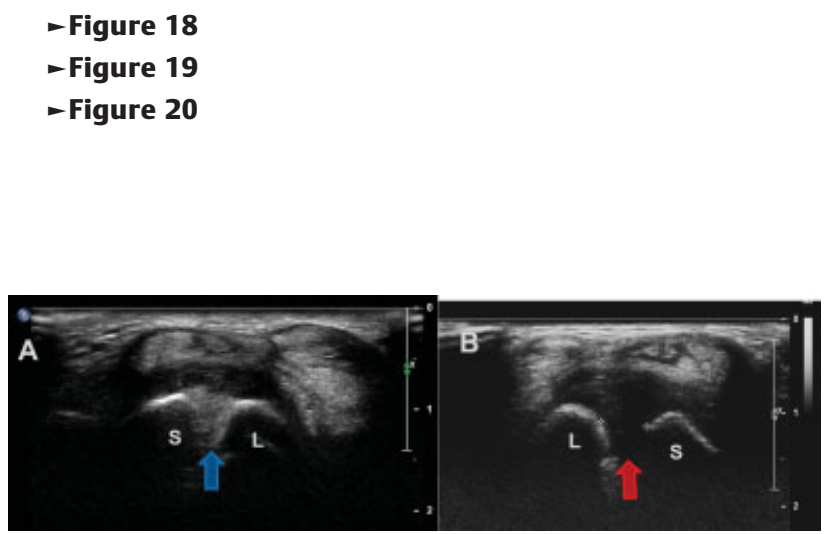

Fig. 18 Image of normal scapholunate ligament and of scapholunate ligament tear 


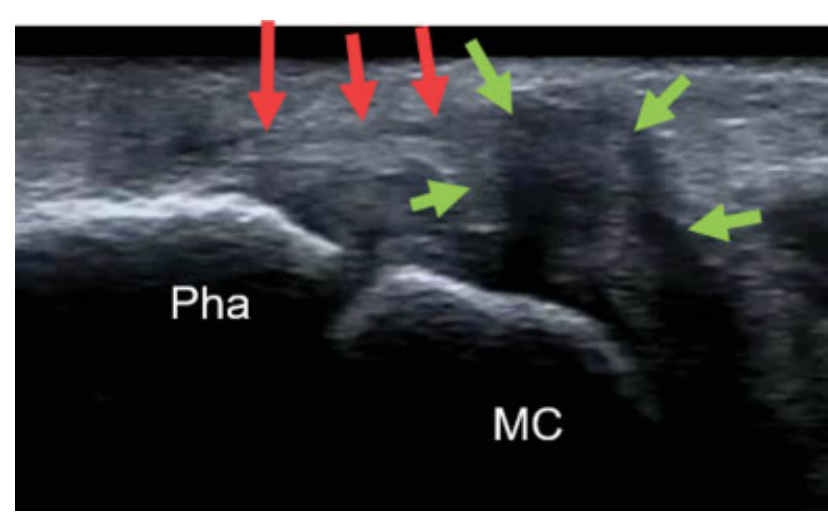

Fig. 19 Stener lesion

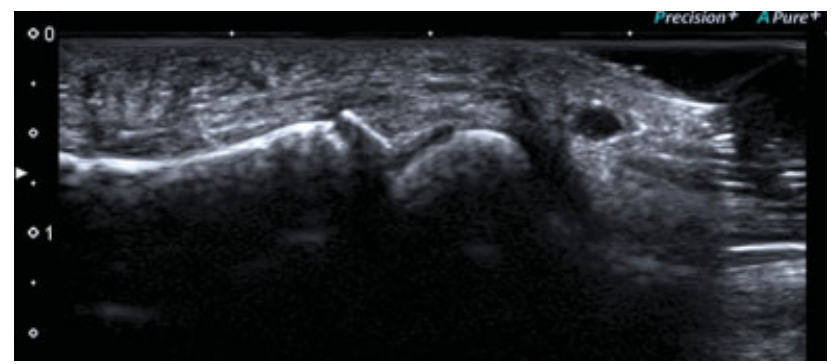

Fig. 20 Volar plate avulsion with bone fragment

\section{Conflict of Interest}

The authors have no conflict of interests to declare.

\section{References}

1 Viviano SL, Chandler LK, Keith JD. Ultrahigh Frequency Ultrasound Imaging of the Hand: A New Diagnostic Tool for Hand Surgery. Hand (N Y) 2018;13(06):720-725

2 Parker L, Nazarian LN, Carrino JA, et al. Musculoskeletal imaging: medicare use, costs, and potential for cost substitution. J Am Coll Radiol 2008;5(03):182-188

3 Guerini H, Morvan G, Vuillemin V, et al. Ultrasound of wrist and hand masses. Diagn Interv Imaging 2015;96(12):1247-1260

4 Sofka CM. Ultrasound of the hand and wrist. Ultrasound Q 2014; 30(03):184-192

5 Starr HM Jr, Sedgley MD, Murphy MS. Ultrasound in hand surgery. J Hand Surg Am 2014;39(12):2522-2524

6 Teefey SA, Dahiya N, Middleton WD, Gelberman RH, Boyer MI. Ganglia of the hand and wrist: a sonographic analysis. AJR Am J Roentgenol 2008;191(03):716-720

7 Lee BJ, Sawyer GA, Dasilva MF. Methylene blue-enhanced arthroscopic resection of dorsal wrist ganglions. Tech Hand Up Extrem Surg 2011;15(04):243-246

8 Teh J. Ultrasound of soft tissue masses of the hand. J Ultrason 2012;12(51):381-401

9 Vreju FA, Ciurea ME, Popa D, et al. Ultrasonography in the diagnosis and management of non inflammatory conditions of the hand and wrist. Med Ultrason 2016;18(01):90-95

10 Rahmani G, McCarthy P, Bergin D. The diagnostic accuracy of ultrasonography for soft tissue lipomas: a systematic review. Acta Radiol Open 2017;6(06):1-6

11 Höglund M, Tordai P, Engkvist O. Ultrasonography for the diagnosis of soft tissue conditions in the hand. Scand J Plast Reconstr Surg Hand Surg 1991;25(03):225-231
12 Schöffl V, Heid A, Kupper T. Tendon injuries of the hand. World J Orthop 2012;3:62-69

13 Karabay N. US findings in traumatic wrist and hand injuries. Diagn Interv Radiol 2013;19(04):320-325

14 Hoffman DF, Adams E, Bianchi S. Ultrasonography of fractures in sports medicine. Br J Sports Med 2015;49(03):152-160

15 Corduff N, Jones R, Ball J. The role of ultrasound in the management of zone 1 flexor tendon injuries. J Hand Surg [Br] 1994;19 (01):76-80

16 Schöffl VR, Schöffl I. Injuries to the finger flexor pulley system in rock climbers: current concepts. J Hand Surg Am 2006;31(04): 647-654

17 Wong DCM, Wansaicheong GKL, Tsou IYY. Ultrasonography of the hand and wrist. Singapore Med J 2009;50(02):219-225

18 Klauser A, Stadlbauer KH, Frauscher F, et al. Value of transducer positions in the measurement of finger flexor tendon thickness by sonography. J Ultrasound Med 2004;23(03):331-337

19 Klauser A, Frauscher F, Bodner G, et al. Finger pulley injuries in extreme rock climbers: depiction with dynamic US. Radiology 2002;222(03):755-761

20 Kessler JM, de la Lama M, Umans HR, Negron J. High-frequency sonography of the volar digital nerves of the hand. Muscle Nerve 2012;45(02):222-226

21 Koenig RW, Pedro MT, Heinen CP, et al. High-resolution ultrasonography in evaluating peripheral nerve entrapment and trauma. Neurosurg Focus 2009;26(02):E13-E15

22 Fornage BD. Peripheral nerves of the extremities: imaging with US. Radiology 1988;167(01):179-182

23 Chiavaras MM, Jacobson JA, Yablon CM, Brigido MK, Girish G. Pitfalls in wrist and hand ultrasound. AJR Am J Roentgenol 2014; 203(03):531-540

24 Davis TR. Prediction of outcome of non-operative treatment of acute scaphoid waist fracture. Ann R Coll Surg Engl 2013;95(03): 171-176

25 Herneth AM, Siegmeth A, Bader TR, et al. Scaphoid fractures: evaluation with high-spatial-resolution US initial results. Radiology 2001;220(01):231-235

26 Olubaniyi BO, Bhatnagar G, Vardhanabhuti V, Brown SE, Gafoor A Suresh PS. Comprehensive musculoskeletal sonographic evaluation of the hand and wrist. J Ultrasound Med 2013;32(06):901-914

27 Taljanovic MS, Goldberg MR, Sheppard JE, Rogers LF. US of the Intrinsic and Extrinsic Wrist Ligaments and Triangular Fibrocartilage Complex-Normal Anatomy and Imaging Technique. Radiographics 2011;31(01):. Doi: 10.1148/rg.e44

28 Finlay K, Lee R, Friedman L. Ultrasound of intrinsic wrist ligament and triangular fibrocartilage injuries. Skeletal Radiol 2004;33 (02):85-90

29 Olchowy C, Łasecki M, Zaleska-Dorobisz U. Wrist ultrasound examination - scanning technique and ultrasound anatomy. Part 1: Dorsal wrist. J Ultrason 2015;15(61):172-188

30 Griffith JF, Chan DP, Ho PC, Zhao L, Hung LK, Metreweli C. Sonography of the normal scapholunate ligament and scapholunate joint space. J Clin Ultrasound 2001;29(04):223-229

31 Kendi AT, Güdemez E. Sonographic evaluation of scapholunate ligament: value of tissue harmonic imaging. J Clin Ultrasound 2006;34(03):109-112

32 Dao KD, Solomon DJ, Shin AY, Puckett ML. The efficacy of ultrasound in the evaluation of dynamic scapholunate ligamentous instability. J Bone Joint Surg Am 2004;86(07):1473-1478

33 Boutry N, Lapegue F, Masi L, Claret A, Demondion X, Cotten A. Ultrasonographic evaluation of normal extrinsic and intrinsic carpal ligaments: preliminary experience. Skeletal Radiol 2005; 34(09):513-521

34 Taljanovic MS, Sheppard JE, Jones MD, Switlick DN, Hunter TB, Rogers LF. Sonography and sonoarthrography of the scapholunate and lunotriquetral ligaments and triangular fibrocartilage disk: 
initial experience and correlation with arthrography and magnetic resonance arthrography. J Ultrasound Med 2008;27(02):179-191 35 Taljanovic MS, Sheppard JE, Jones MD, Switlick DN, Hunter TB, Rogers LF. Sonography and sonoarthrography of the scapholunate and lunotriquetral ligaments and TFC: initial experience and correlation with arthrography and magnetic resonance arthrography. J Ultrasound Med 2008;27(02):179-191
36 Ebrahim FS, De Maeseneer M, Jager T, Marcelis S, Jamadar DA, Jacobson JA. US diagnosis of UCL tears of the thumb and Stener lesions: technique, pattern-based approach, and differential diagnosis. Radiographics 2006;26(04):1007-1020

37 Boutry N, Lardé A, Demondion X, Cortet B, Cotten H, Cotten A. Metacarpophalangeal joints at US in asymptomatic volunteers and cadaveric specimens. Radiology 2004;232(03):716-724 